\title{
Characterizing the Countrywide Epidemic Spread of Influenza A(H1N1)pdm09 Virus in Kenya between 2009 and 2018
}

\author{
D. Collins Owuor 1,*, Zaydah R. de Laurent ${ }^{1}$, Gilbert K. Kikwai ${ }^{2}$, Lillian M. Mayieka ${ }^{2}$, Melvin Ochieng ${ }^{2}$, \\ Nicola F. Müller ${ }^{3}$, Nancy A. Otieno ${ }^{2}$, Gideon O. Emukule 4, Elizabeth A. Hunsperger 5,6, Rebecca Garten 7 , \\ John R. Barnes 7, Sandra S. Chaves ${ }^{4,7}$, D. James Nokes ${ }^{1,8}$ and Charles N. Agoti 1,9
}

Citation: Owuor, D.C.; de Laurent, Z.R.; Kikwai, G.K.; Mayieka, L.M.; Ochieng, M.; Müller, N.F.; Otieno, N.A.; Emukule, G.O.; Hunsperger, E.A.; Garten, R.; et al. Characterizing the Countrywide Epidemic Spread of Influenza A(H1N1)pdm09 Virus in Kenya between 2009 and 2018. Viruses 2021, 13, 1956. https:// doi.org/10.3390/v13101956

Academic Editors: Samantha Lycett and Paul Digard

Received: 29 July 2021

Accepted: 22 September 2021 Published: 29 September 2021

Publisher's Note: MDPI stays neutral with regard to jurisdictional claims in published maps and institutional affiliations.

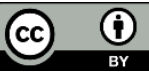

Copyright: (C) 2021 by the authors. Licensee MDPI, Basel, Switzerland. This article is an open access article distributed under the terms and conditions of the Creative Commons Attribution (CC BY) license (http://creativecommons.org/licenses/by/4.0/).
1 Wellcome Trust Research Programme, Epidemiology and Demography Department, Kenya Medical Research Institute (KEMRI), Kilifi 230-80108, Kenya; ZDeLaurent@kemri-wellcome.org (Z.R.d.L.); jnokes@kemri-wellcome.org (D.J.N.); cnyaigoti@kemri-wellcome.org (C.N.A.)

2 Kenya Medical Research Institute (KEMRI), Nairobi 54840-00200, Kenya; GKikwai@kemricdc.org (G.K.K.); LMayieka@kemri.org (L.M.M.); MOchieng@kemricdc.org (M.O.); Notieno@kemricdc.org (N.A.O.)

3 Fred Hutchinson Cancer Research Center, Vaccine and Infectious Disease Division, Seattle, WA 98109, USA; nicola.felix.mueller@gmail.com

4 Centers for Disease Control and Prevention (CDC), Influenza Division, Nairobi 606-00621, Kenya; uyr9@cdc.gov (G.O.E.); Sandra.Chaves@sanofi.com (S.S.C.)

5 Centers for Disease Control and Prevention, Division of Global Health Protection, Nairobi 606-00621, Kenya; enh4@cdc.gov

6 Centers for Disease Control and Prevention, Division of Global Health Protection, Atlanta, GA 30333, USA

7 Influenza Division, National Center for Immunization and Respiratory Diseases (NCIRD), Centers for Disease Control and Prevention, Atlanta, GA 30333, USA; dqy5@cdc.gov (R.G.); fzq9@cdc.gov (J.R.B.)

8 School of Life Sciences and Zeeman Institute for Systems Biology and Infectious Disease Epidemiology Research (SBIDER), Coventry CV4 7AL, UK

9 School of Public Health and Human Sciences, Pwani University, Kilifi 195-80108, Kenya

* Correspondence: dcollins@kemri-wellcome.org

\begin{abstract}
The spatiotemporal patterns of spread of influenza A(H1N1)pdm09 viruses on a countrywide scale are unclear in many tropical/subtropical regions mainly because spatiotemporally representative sequence data are lacking. We isolated, sequenced, and analyzed 383 A(H1N1)pdm09 viral genomes from hospitalized patients between 2009 and 2018 from seven locations across Kenya. Using these genomes and contemporaneously sampled global sequences, we characterized the spread of the virus in Kenya over several seasons using phylodynamic methods. The transmission dynamics of $\mathrm{A}(\mathrm{H} 1 \mathrm{N1})$ pdm09 virus in Kenya were characterized by (i) multiple virus introductions into Kenya over the study period, although only a few of those introductions instigated local seasonal epidemics that then established local transmission clusters, (ii) persistence of transmission clusters over several epidemic seasons across the country, (iii) seasonal fluctuations in effective reproduction number $\left(R_{\mathrm{e}}\right)$ associated with lower number of infections and seasonal fluctuations in relative genetic diversity after an initial rapid increase during the early pandemic phase, which broadly corresponded to epidemic peaks in the northern and southern hemispheres, (iv) high virus genetic diversity with greater frequency of seasonal fluctuations in 2009-2011 and 2018 and low virus genetic diversity with relatively weaker seasonal fluctuations in 2012-2017, and (v) virus spread across Kenya. Considerable influenza virus diversity circulated within Kenya, including persistent viral lineages that were unique to the country, which may have been capable of dissemination to other continents through a globally migrating virus population. Further knowledge of the viral lineages that circulate within understudied low-to-middle-income tropical and subtropical regions is required to understand the full diversity and global ecology of influenza viruses in humans and to inform vaccination strategies within these regions.
\end{abstract}

Keywords. next-generation sequencing; hemagglutinin; phylodynamics; transmission 


\section{Introduction}

The novel influenza A(H1N1)pdm09 virus strain emerged in North America during March-April 2009, spread rapidly among humans, and developed into the first human pandemic of the 21st century [1-4]. By July 2009, 168 countries reported a total of 162,300 laboratory-confirmed cases and over 1100 human deaths [5-7]. Subsequently, it was estimated that globally over 123,000 deaths from March to December 2009 were associated with $\mathrm{A}(\mathrm{H} 1 \mathrm{~N} 1) \mathrm{pdm} 09$ virus infection [8]. The $\mathrm{A}(\mathrm{H} 1 \mathrm{~N} 1) \mathrm{pdm} 09$ virus displaced the seasonal $\mathrm{A}(\mathrm{H} 1 \mathrm{~N} 1)$ virus and has continued to circulate as a seasonal virus in subsequent years, causing annual seasonal epidemics alongside influenza $\mathrm{A}(\mathrm{H} 3 \mathrm{~N} 2)$ and $\mathrm{B}$ viruses globally [9-12], including in Kenya [13-17].

The global surveillance of influenza viruses has resulted in the generation of an extensive collection of geographically and temporally comprehensive virus sequence data, which has provided an opportunity to explore the drivers of global spread of influenza viruses [18-22]. For instance, genomic analysis found that multiple independent introductions of genetically distinct $\mathrm{A}(\mathrm{H} 1 \mathrm{~N} 1) \mathrm{pdm} 09$ virus lineages occurred in most countries; in the United Kingdom, only two of the many lineages that were introduced at the start of the pandemic were detected there 6 months later $[9,23]$. Elsewhere, a pair of $\mathrm{A}(\mathrm{H} 1 \mathrm{~N} 1) \mathrm{pdm} 09$ virus transmission chains appeared to have persisted in west Africa for almost 2 years [24]. Since the $\mathrm{A}(\mathrm{H} 1 \mathrm{~N} 1) \mathrm{pdm} 09$ virus became endemic, such spatiotemporal patterns of spread of $\mathrm{A}(\mathrm{H} 1 \mathrm{~N} 1) \mathrm{pdm} 09$ viruses on a countrywide scale have, however, not been determined in many tropical/subtropical regions where virus circulation patterns do not show a clear seasonality as they do in temperate countries $[25,26]$. This is often due to insufficient spatiotemporally representative sequence data $[27,28]$. A more complete understanding of the regional and the global spread of influenza viruses, however, requires deeper and wider sampling from understudied tropical/subtropical regions [28].

Surveillance of influenza viruses is ongoing in several parts of Kenya [13,17,29,30]. These are carried out by the Kenya Medical Research Institute (KEMRI), Ministry of Health, Kenya, KEMRI-Wellcome Trust Research Program (KWTRP), and the USA Army Medical Research Directorate (USAMRD-K). In 2007, the Ministry of Health, Kenya with technical support from the Centers for Disease Control (CDC) Kenya country office (CDC-Kenya) established a National Influenza Surveillance System in response to the 2005 influenza A(H5N1) virus threat. The aims of the surveillance system were to identify circulating strains of influenza virus, describe the epidemiology and burden of influenza in Kenya, and serve as a component of an early warning system for pandemic influenza [13]. CDC-Kenya conducts surveillance for influenza and influenza-like illness (ILI) and severe acute respiratory illness (SARI) throughout the country; these are conducted in sentinel hospitals, health facilities at demographic surveillance sites, and refugee camps, which represent varied urban, rural, high mobility, and socioeconomic conditions [13]. The KWTRP Virus Epidemiology and Control (VEC) team established research collaboration with CDC-Kenya through a joint study and a countrywide pathway of transmission study entitled "Studies of the pathways of transmission of respiratory virus disease" (SPReD-Kenya)-http://virec-group.org/spred-kenya/ (accessed on 10 September 2021), which also provided samples for this study.

Influenza surveillance activities in Kenya reported at least four separate introductions of $\mathrm{A}(\mathrm{H} 1 \mathrm{~N} 1) \mathrm{pdm} 09$ virus into the country during the pandemic in 2009, with the first laboratory-confirmed case reported on 29 June 2009 [31,32]. In an effort to fill the gap in studies that seek to describe the transmission of influenza viruses in tropical settings, we studied the Kenya-wide patterns of introduction and spread of $\mathrm{A}(\mathrm{H} 1 \mathrm{~N} 1)$ pdm09 virus since it was introduced into the local population in 2009. We isolated, sequenced, and analyzed $383 \mathrm{~A}(\mathrm{H} 1 \mathrm{~N} 1) \mathrm{pdm} 09$ virus codon-complete genome sequences sampled between 2009 and 2018 from seven locations in Kenya alongside contemporaneously sampled global sequences, to investigate the introduction and spread of $\mathrm{A}(\mathrm{H} 1 \mathrm{~N} 1) \mathrm{pdm} 09$ viruses to Kenya. 


\section{Materials and Methods}

\subsection{Sample Sources and Molecular Screening}

Samples analyzed in this study were collected through two health facility-based surveillance networks. The first involved continuous countrywide surveillance for influenza through SARI sentinel hospital reporting. This was undertaken at six sites supported by CDC-Kenya: Kenyatta National Hospital (KNH), Nakuru County and Referral Hospital (CRH), Nyeri CRH, Kakamega CRH, Siaya CRH, and Coast General Teaching and Referral Hospital (Figure S1) [13,14,16,33]. The second was the pediatric viral pneumonia surveillance undertaken at the Kilifi County Hospital (KCH) (Figure S1) [29].

In the CDC-supported surveillance sites, a total of 41,685 nasopharyngeal/oropharyngeal (NP/OP) swab samples were collected from SARI inpatient admissions of all ages from June 2009 through December 2018. Samples were stored in viral transport medium (VTM) at $-80^{\circ} \mathrm{C}$ prior to processing [13]. Of these, 41,102 swabs were tested for influenza $A$ virus (IAV), with positive samples subsequently subtyped for A(H1N1)pdm09 and $\mathrm{A}(\mathrm{H} 3 \mathrm{~N} 2)$ viruses using real-time reverse transcription polymerase chain reaction (RTPCR) [13,14,16]. A total of 1307 (3.2\%) A(H1N1)pdm09 virus-positive samples were obtained. Of these, 418 (31.9\%) A(H1N1)pdm09 virus=positive samples were selected for this analysis on the basis of an RT-PCR cycle threshold (Ct) of $<35.0$ (as a proxy for high viral load), an adequate sample volume for RNA extraction $(>140 \mu \mathrm{L})$, and a balanced distribution of samples based on surveillance sites and years.

In the second facility-based surveillance undertaken at $\mathrm{KCH}$ from January 2009 through December 2018, a total of 6147 NP/OP swab samples were collected and tested from children $<5$ years admitted with syndromic severe or very severe pneumonia $[15,29]$. Samples were stored in VTM at $-80{ }^{\circ} \mathrm{C}$ prior to molecular screening. Samples were screened for a range of respiratory viruses, including IAV, using a multiplex real-time reverse transcription (RT)-PCR assay employing Qiagen QuantiFast RT-PCR kit (Qiagen, Hilden, Germany) [34]. An (RT)-PCR Ct of $<35.0$ was used to define virus-positive samples [34]. A total of 157 (2.6\%) IAV-positive specimens were identified from $\mathrm{KCH}$; however, these were not subsequently subtyped for $\mathrm{A}(\mathrm{H} 1 \mathrm{~N} 1) \mathrm{pdm} 09$ and $\mathrm{A}(\mathrm{H} 3 \mathrm{~N} 2)$ viruses [29]. Therefore, all IAV-positive specimens were utilized, and only the A(H1N1)pdm09 viruses were selected for the current analysis.

\subsection{RNA Extraction and Multi-Segment Real-Time PCR (M-RTPCR) for IAV}

Viral RNA extraction and M-RTPCR were conducted as previously described [35]. Briefly, viral nucleic acid extraction from IAV and A(H1N1)pdm09 virus-positive samples was performed using the QIAamp Viral RNA Mini Kit (Qiagen, Hilden, Germany). Ribonucleic acid (RNA) was reverse-transcribed, and the complete coding region of IAV genome was amplified in a single M-RTPCR using the Uni/Inf primer set [36] in $25 \mu \mathrm{L}$ PCR reactions. Successful amplification was evaluated by running the products on $2 \%$ agarose gel and visualized on a UV transilluminator after staining with RedSafe Nucleic Acid Staining solution (iNtRON Biotechnology Inc., Seoul, South Korea).

\subsection{IAV Next-Generation Sequencing (NGS) and Virus Genome Assembly}

Following PCR, amplicons were purified, quantitated, and normalized to $0.2 \mathrm{ng} / \mu \mathrm{L}$ as previously described [35]. Briefly, following PCR, the amplicons were purified with $1 \times$ AMPure XP Beads (Beckman Coulter Inc., Brea, CA, USA), quantified with Quant-iT dsDNA High Sensitivity Assay (Invitrogen, Carlsbard, CA, USA), and normalized to 0.2 $\mathrm{ng} / \mu \mathrm{L}$. Indexed paired end libraries were generated from $2.5 \mu \mathrm{L}$ of $0.2 \mathrm{ng} / \mu \mathrm{L}$ amplicon pool using a Nextera XT Sample Preparation Kit (Illumina, San Diego, CA, USA) following the manufacturer's protocol. Amplified libraries were purified using $0.8 \times$ AMPure XP beads, quantitated using Quant-iT dsDNA High Sensitivity Assay (Invitrogen, Carlsbard, CA, USA), and evaluated for fragment size in the Agilent 2100 BioAnalyzer System using 
the Agilent High Sensitivity DNA Kit (Agilent Technologies, Santa Clara, CA, USA). Amplicon libraries were then diluted to $2 \mathrm{nM}$ in preparation for pooling and denaturation for running on the Illumina MiSeq (Illumina, San Diego, CA, USA). Pooled libraries were denatured with sodium hydroxide, diluted to $12.5 \mathrm{pM}$, and sequenced on the Illumina MiSeq using $2 \times 250$ base pair (bp) paired-end reads with MiSeq v2 500 Cycle Kit (Illumina, San Diego, CA, USA). A 5\% Phi-X (Illumina, San Diego, CA, USA) spike-in was added to the libraries to increase library diversity by creating a more diverse set of library clusters. Contiguous nucleotide sequence assembly from the sequence data was carried out using the FLU module of the Iterative Refinement Meta-Assembler (IRMA) [37] using IRMA default settings: median read Q-score filter of 30; minimum read length of 125; frequency threshold for insertion and deletion refinement of 0.25 and 0.6, respectively; Smith-Waterman mismatch penalty of 5; gap opening penalty of 10 . All generated sequence data were deposited in the Global Initiative on Sharing All Influenza Data (GISAID) EpiFluTM database (https://platform.gisaid.org/epi3/cfrontend; accessed on 10 March 2021) using accession numbers listed in the metadata file in the report's GitHub repository https://github.com/DCollinsOwuor/H1N1pdm09_Kenya_Phylodynamics/tree/main/

Data/; accessed on 11 March 2021.

\subsection{Phylogenetic Analysis}

Consensus nucleotide sequences were aligned using MUSCLE (https://www.ebi.ac.uk/Tools/msa/muscle/; accessed on 11 March 2021) and translated in AliView v1.26 [38], and the individual gene segments of Kenyan sequences were concatenated into codon-complete genomes using SequenceMatrix v1.7.8 [39]. Phylogenetic trees of $\mathrm{A}(\mathrm{H} 1 \mathrm{~N} 1) \mathrm{pdm} 09$ virus genomes from Kenya and contemporaneously sampled global sequences were reconstructed with maximum-likelihood and bootstrap analysis of 1000 replicates. The best-fit nucleotide substitution models were inferred using IQ-TREE v1.6.11 [40,41] and those chosen by the Bayesian Information Criterion for each concatenated virus genome implemented. The phylogenetic trees were visualized and annotated using Figtree v1.4.4 (http://tree.bio.ed.ac.uk/software/figtree/; accessed on 12 March 2021) and ggtree [42]. The full-length hemagglutinin (HA) codon sequences of all viruses were used to characterize $\mathrm{A}(\mathrm{H} 1 \mathrm{~N} 1) \mathrm{pdm} 09$ virus strains into genetic groups (i.e., clades, subclades, and subgroups) using Phylogenetic Clustering with Linear Integer Programming (PhyCLIP) [43] and the European CDC Guidelines (https://www.ecdc.europa.eu/en/seasonal-influenza/surveillance-and-disease-data/influenza-virus-characterisation; accessed on 12 March 2021). Representative reference sequences for genetic clade assignment were included.

\subsection{Estimating Population Dynamics of A(H1N1)pdm09 Virus in Kenya from Local Transmission Clusters}

To analyze the introduction and local spread of A(H1N1)pdm09 virus in Kenya, we first differentiated between "transmission clusters" and "single introductions". Transmission clusters were defined as groups of sequences that originated from a single introduction into Kenya. Ancestral state reconstruction of internal nodes based on Kenyan and global sequences was used to infer these transmission clusters using a maximum-likelihood approach in TreeTime [44]. To do so, all the sequences were assigned into two discrete location states: (i) Kenyan-all Kenyan sequences, and (ii) non-Kenyan-all sequences from anywhere else from the globe. All sequences that clustered together were considered to belong in the same transmission cluster if their common ancestral nodes were inferred to be in Kenya, whereas each individual transmission cluster was considered to be the result of a single introduction into Kenya. Clusters were named to reflect their placement within global genetic clades 1-7, for example, KENI-GC7 indicates Kenya cluster I viruses within global genetic clade 7. According to the identified transmission clusters, we utilized the metadata file and script available at https://github.com/DCollinsOwuor/H1N1pdm09_Kenya_Phylodynamics/tree/main/Analysis (accessed on 11 
March 2021) to re-estimate the number of introductions in $\mathrm{R}$ programming software v4.0.2. The transmission clusters were then used to analyze the spread of $\mathrm{A}(\mathrm{H} 1 \mathrm{~N} 1) \mathrm{pdm} 09$ virus in Kenya using two phylodynamic approaches. First, the effective reproduction number $\left(R_{\mathrm{e}}\right)$, which is the average number of secondary cases generated by an infection, was estimated using a birth-death skyline (BDSKY) analysis [45], where all individual transmission clusters are assumed to be independent observations of the same process with the same parameters [46]. Second, the relative genetic diversity (effective virus population size over time) was estimated using Gaussian Markov random field (GMRF) coalescent smoothing of the effective population size [47].

\subsection{Spatial Dynamics of A(H1N1)pdm09 Virus in Kenya}

We conducted phylogeographic analysis to assess virus spread among three geographical regions of Kenya: (i) central Kenya-Nairobi, Nakuru, and Nyeri, (ii) western Kenya-Siaya and Kakamega, and (iii) coastal Kenya-Mombasa and Kilifi (Figure S1) using methods implemented in BEAST v1.10.4 package [48]. The analysis was implemented with an asymmetrical discrete trait approach and applied the Bayesian stochastic search variable selection (BSSVS) model [49]. Phylogeographic inferences were visualized with the Spatial Phylogenetic Reconstruction of Evolutionary Dynamics using DataDriven Documents (SPREAD3) software v0.9.7.1c [50]. To visualize the geographic spread of the virus over time, a D3 file was generated using SPREAD3 v0.9.7.1c. A Kenya geo.json file was used for visualization, and the resulting log files were used to calculate Bayes factor $(\mathrm{BF})$ values for significant dispersal rates between discrete locations.

\section{Results}

\subsection{IAV Sequencing and Genome Assembly}

Among the $418 \mathrm{~A}(\mathrm{H} 1 \mathrm{~N} 1) \mathrm{pdm} 09$ virus-positive samples that were available from the CDC-Kenya surveillance system, $414(99.1 \%)$ passed pre-sequencing quality control checks and were loaded onto the MiSeq (Figure S2). This yielded 344 (83.1\%) codon-complete and $66(15.9 \%)$ partial $\mathrm{A}(\mathrm{H} 1 \mathrm{~N} 1)$ pdm09 virus genomes; four of the sequenced genomes were not successfully assembled due to a low number of IAV sequence reads. For this analysis, only the 344 codon-complete $\mathrm{A}(\mathrm{H} 1 \mathrm{~N} 1) \mathrm{pdm} 09$ virus genome sequences were included. Among the $157 \mathrm{IAV}$-positive specimens available from $\mathrm{KCH}, 94(59.9 \%)$ that passed pre-sequencing quality control checks were loaded onto the MiSeq; the 63 (40.1\%) specimens that were not sequenced had inadequate sample volumes for RNA extraction $(<140 \mu \mathrm{L})$ and failed pre-sequencing quality control checks (Figure S2). A total of 45 (47.9\%) A(H1N1)pdm09 virus (39 codon-complete and six partial) and 49 (52.1\%) $\mathrm{A}(\mathrm{H} 3 \mathrm{~N} 2)$ virus genomes (46 codon-complete and three partial) were successfully generated from sequencing. Only the 39 codon-complete $\mathrm{A}(\mathrm{H} 1 \mathrm{~N} 1) \mathrm{pdm} 09$ virus sequences were included in these analyses (Figure S2).

\subsection{Spatiotemporal Distribution of Sequenced Samples}

The A(H1N1)pdm09 virus was detected throughout the study period in Kenya, with the number of observed cases fluctuating from year to year (Figure 1A). Different locations experienced epidemic peaks in different years. However, there were $\mathrm{A}(\mathrm{H} 1 \mathrm{~N} 1) \mathrm{pdm} 09$ virus detections in all sites, except in mid-2010, 2012-2013, and 2016, when there was little transmission of $\mathrm{A}(\mathrm{H} 1 \mathrm{~N} 1) \mathrm{pdm} 09$ virus throughout the different sites (Figure 1A). The proportion of sequenced samples roughly reflected the overall distribution of positives that were detected from each site (Figure 1A). All A(H1N1)pdm09 virus genetic groups were detected in most sites, with their majority detected in five or six of the seven sites, which suggests that these lineages were in circulation in most of the sites in Kenya without geographical restrictions during the study period (Figure 1B). Phylogenetic analysis showed that the sequenced $383 \mathrm{~A}(\mathrm{H} 1 \mathrm{~N} 1) \mathrm{pdm} 09$ viruses from Kenya comprised seven genetic groups: clade $7(n=97,25.3 \%)$, clade $6(n=132,34.5 \%)$, subclade $6 \mathrm{C}(n=10,2.6 \%)$, subclade 
6B $(n=47,12.3 \%)$, subclade 6B.1 $(n=38,9.9 \%)$, subgroup 6B.1A $(n=57,14.9 \%)$, and subgroup 6B.1A1 ( $n=2,0.5 \%)$ (Figure 2). These detections varied by surveillance year: clade 7-2009-2012; clade 6-2009-2011; subclade 6C-2013-2014; subclade 6B-2014-2016; subgroup 6B.1-2015-2016; subgroup 6B.1A and subgroup 6B.1A1-2018 (Figure 1C).
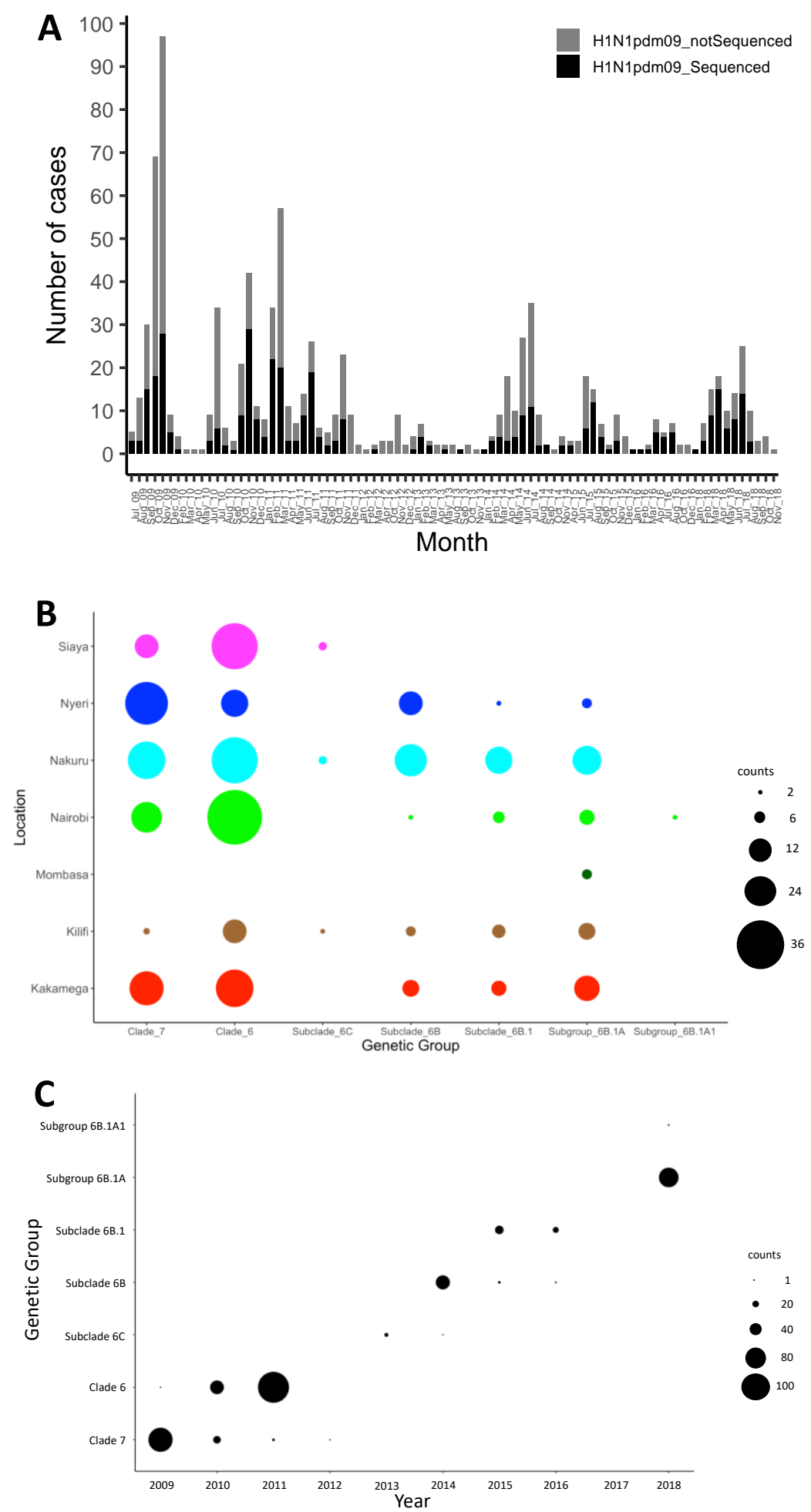

Figure 1. Distribution of influenza A(H1N1)pdm09 virus in Kenya, 2009-2018. (A) Bar plot showing number of $\mathrm{A}(\mathrm{H} 1 \mathrm{~N} 1)$ pdm09 virus-positive samples and sequenced positive samples by month between July 2009 and November 2018 in Kenya. All collected A(H1N1)pdm09 virus-positive samples and sequenced samples are indicated by color (all positive samples in grayH1N1pdm09_notSequenced; sequenced samples in black-H1N1pdm09_Sequenced) as shown in 
the color key. (B) Bubble plot showing the distribution of genetic groups by location in Kenya, 20092018. (C) Distribution of genetic groups by surveillance year in Kenya, 2009-2018. The size of the circles in panels $(\mathbf{B}, \mathbf{C})$ is proportional to the number of samples, as shown in the counts key for the figures.

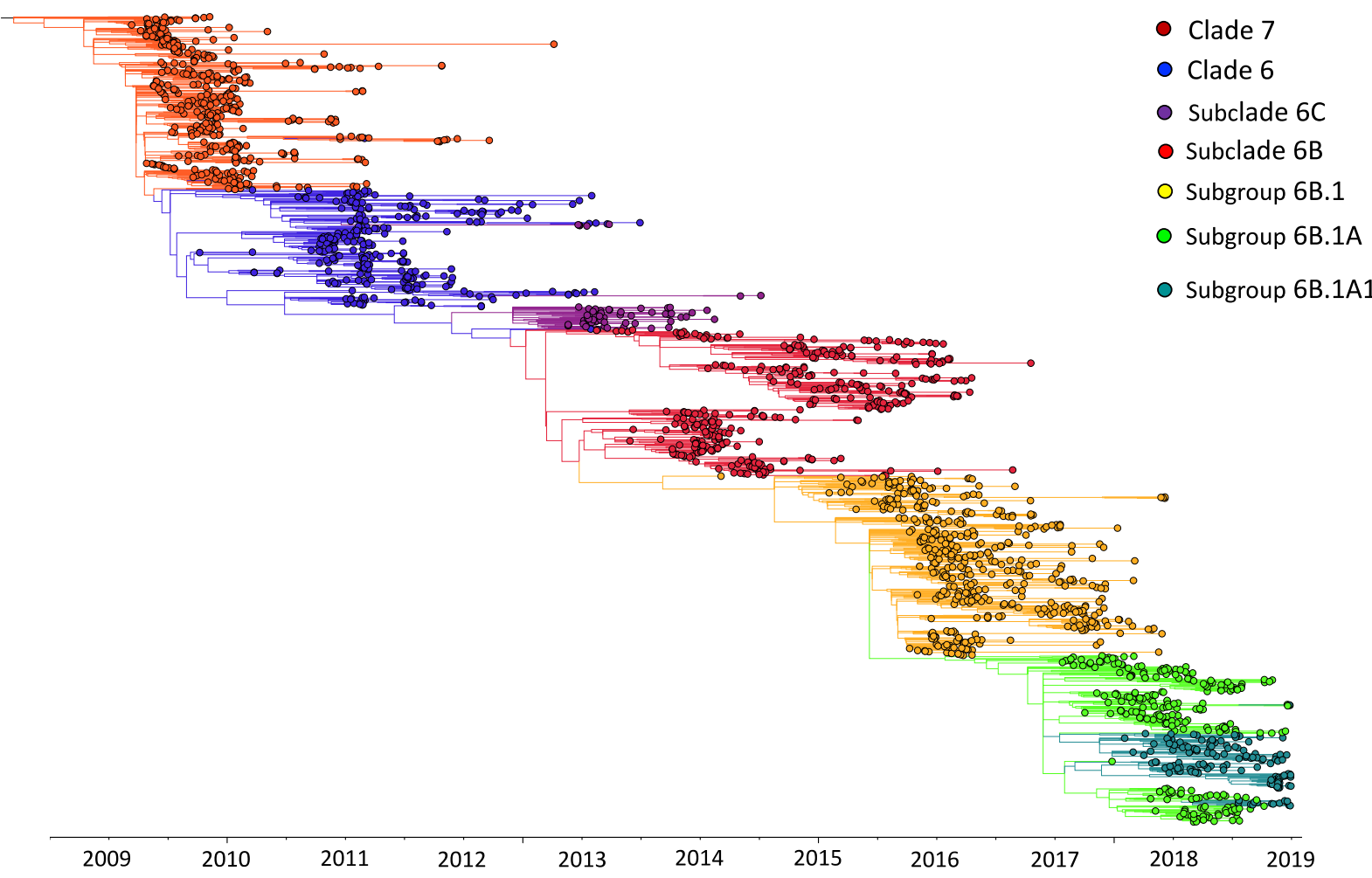

Figure 2. Maximum-likelihood phylogenetic tree of 1970 influenza A(H1N1)pdm09 virus sequences from Kenya and contemporaneously sampled global locations collected between 2009 and 2018. This is a time-calibrated phylogeny with time shown on the $x$-axis. Branches are colored on the basis of genetic group membership, as shown in the color key.

\subsection{Patterns of Introduction of A(H1N1)pdm09 Viruses into Kenya and Local Transmission Clusters}

We first assessed how the 383 sequences from Kenya compared to 1587 sequences sampled from around the world between 2009 and 2018 (Supplementary Materials-Collation of contemporaneous global sequence dataset) by inferring their phylogenies. The Kenyan genomes spanned the existing global diversity (Figure 3), which suggests exchange (most likely introductions into Kenya) of viruses with other areas around the globe. For example, phylogenetic tree trunk viruses predominantly originated from North America in 2009, consistent with the origins of A(H1N1)pdm09 virus in North America in 2009, which seeded global viruses in 2009-2010. Subsequently, Asia and Europe appeared to be the major source populations in 2010-2013 and 2014-2018, respectively (Figure 3). The three geographical regions also represent sources of introduction of $\mathrm{A}(\mathrm{H} 1 \mathrm{~N} 1) \mathrm{pdm} 09$ virus into Kenya in 2009, 2010-2013, and 2014-2018. On the basis of a reconstruction of geographic ancestry, Kenyan sequences grouped into local transmission clusters within the global diversity (Figure 3). We inferred 30 transmission clusters (KENI-GC7 to KENXXX-GC6B.1A) (Figure 3), which suggests that the sampled sequences were the result of 30 independent introductions from areas outside of Kenya. However, despite the relatively strong clustering of Kenyan sequences into transmission clusters, there were relatively few $(8 / 30)$ introductions that resulted in local epidemics. To investigate if this number was a strict lower bound for the introductions, we used random subsets of the 383 $\mathrm{A}(\mathrm{H} 1 \mathrm{~N} 1) \mathrm{pdm} 09$ virus sequences from Kenya to re-estimate the number of introductions (Figure 4). We found that the number of estimated introductions started to flatten slightly 
with the number of sequences subsampled but still grew. This saturating relationship suggests that the study did not grossly underestimate the full number of A(H1N1)pdm09 virus variants in this report. Seven of the 30 transmission clusters appeared to have persisted over several epidemic seasons (Table 1), which provides evidence for multiyear persistence of individual $\mathrm{A}(\mathrm{H} 1 \mathrm{~N} 1) \mathrm{pdm} 09$ virus transmission clusters in a specific locality. All seven transmission clusters that persisted between 2009 and 2018 consisted of viruses sampled across Kenya, which suggests that $\mathrm{A}(\mathrm{H} 1 \mathrm{~N} 1) \mathrm{pdm} 09$ virus persistence in the country was not constrained geographically.

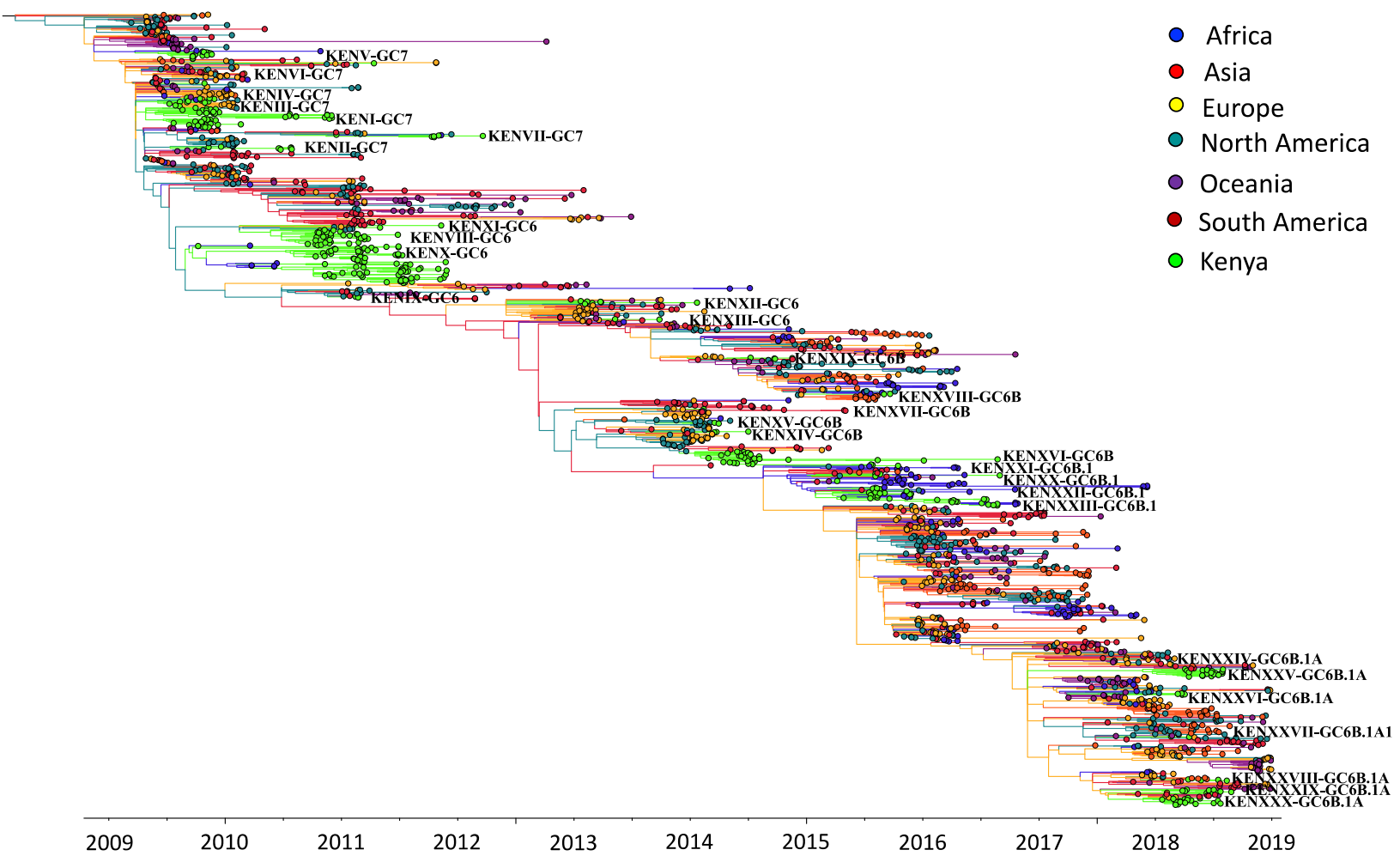

Figure 3. Time-resolved maximum-likelihood phylogenetic tree of Kenyan and contemporaneously sampled global sequences collected between 2009 and 2018 showing continent of sequence sampling and Kenyan transmission clusters. Unique Kenyan clusters are labeled with the prefix KEN, followed by cluster grouping and genetic group; for example, KENI-GC7 indicates Kenyan cluster I viruses, which fall within global genetic clade 7 . The branches are colored on the basis of continent of sampling, as shown in the color key. Additionally, the trunk locations are inferred and colored by continent, which is based on geographic ancestry analyses of sampled sequences to indicate influenza A(H1N1)pdm09 virus origins.

Table 1. Patterns of persistence of $\mathrm{A}(\mathrm{H} 1 \mathrm{~N} 1) \mathrm{pdm} 09$ virus transmission clusters in Kenya.

\begin{tabular}{ccccccc}
\hline t Cluster & Clade & Sequences & From & Circulation & Duration of Spread & Locations Detected \\
\hline KENI-GC-7 & 7 & 49 & Europe & $\begin{array}{c}\text { July 2009 to Decem- } \\
\text { ber 2010 }\end{array}$ & 1.5 years & $\begin{array}{c}\text { Nairobi; Nakuru; } \\
\text { Nyeri; Siaya; Kilifi }\end{array}$ \\
\hline KENVII-GC7 & 7 & 6 & North America & $\begin{array}{c}\text { December 2010 to } \\
\text { March 2012 }\end{array}$ & 1.3 years & $\begin{array}{c}\text { Nairobi; Nakuru; Ka- } \\
\text { kamega }\end{array}$ \\
\hline KENVIII-GC6 & 6 & 39 & North America & $\begin{array}{c}\text { October 2010 to } \\
\text { June 2011 }\end{array}$ & 9 months & $\begin{array}{c}\text { Nairobi; Nakuru; Ka- } \\
\text { kamega; Nyeri; Siaya; } \\
\text { Kilifi }\end{array}$ \\
\hline KENX-GC6 & 6 & 88 & North America October 2009 to No- & 2.2 years & $\begin{array}{c}\text { Nairobi; Nakuru; Ka- } \\
\text { kamega; Nyeri; Siaya; } \\
\text { Kilifi }\end{array}$ \\
\hline
\end{tabular}




\begin{tabular}{ccccccc}
\hline KENXII-GC6C & 6C & 8 & Europe & $\begin{array}{c}\text { January 2013 to Jan- } \\
\text { uary 2014 }\end{array}$ & 1 year & Nakuru; Siaya \\
\hline KENXVI-GC6B & 6B & 34 & North America & $\begin{array}{c}\text { February 2014 to } \\
\text { August 2016 }\end{array}$ & 2.5 years & $\begin{array}{c}\text { Nairobi; Nakuru; Ka- } \\
\text { kamega; Nyeri; Kilifi }\end{array}$ \\
\hline $\begin{array}{c}\text { KENXXIII- } \\
\text { GC6B.1 }\end{array}$ & 6B.1 & 34 & Europe & $\begin{array}{c}\text { April 2015 to Au- } \\
\text { gust 2016 }\end{array}$ & 1.3 years & $\begin{array}{c}\text { Nairobi; Nakuru; Ka- } \\
\text { kamega; Nyeri; Kilifi }\end{array}$ \\
\hline
\end{tabular}

+ Cluster, name of transmission cluster; Clade, genetic group membership; Sequences, number of sequences in cluster; From, inferred geographical source of virus introduction; Circulation, duration of circulation of the cluster in Kenya; Locations Detected, Kenyan locations where clusters were detected.

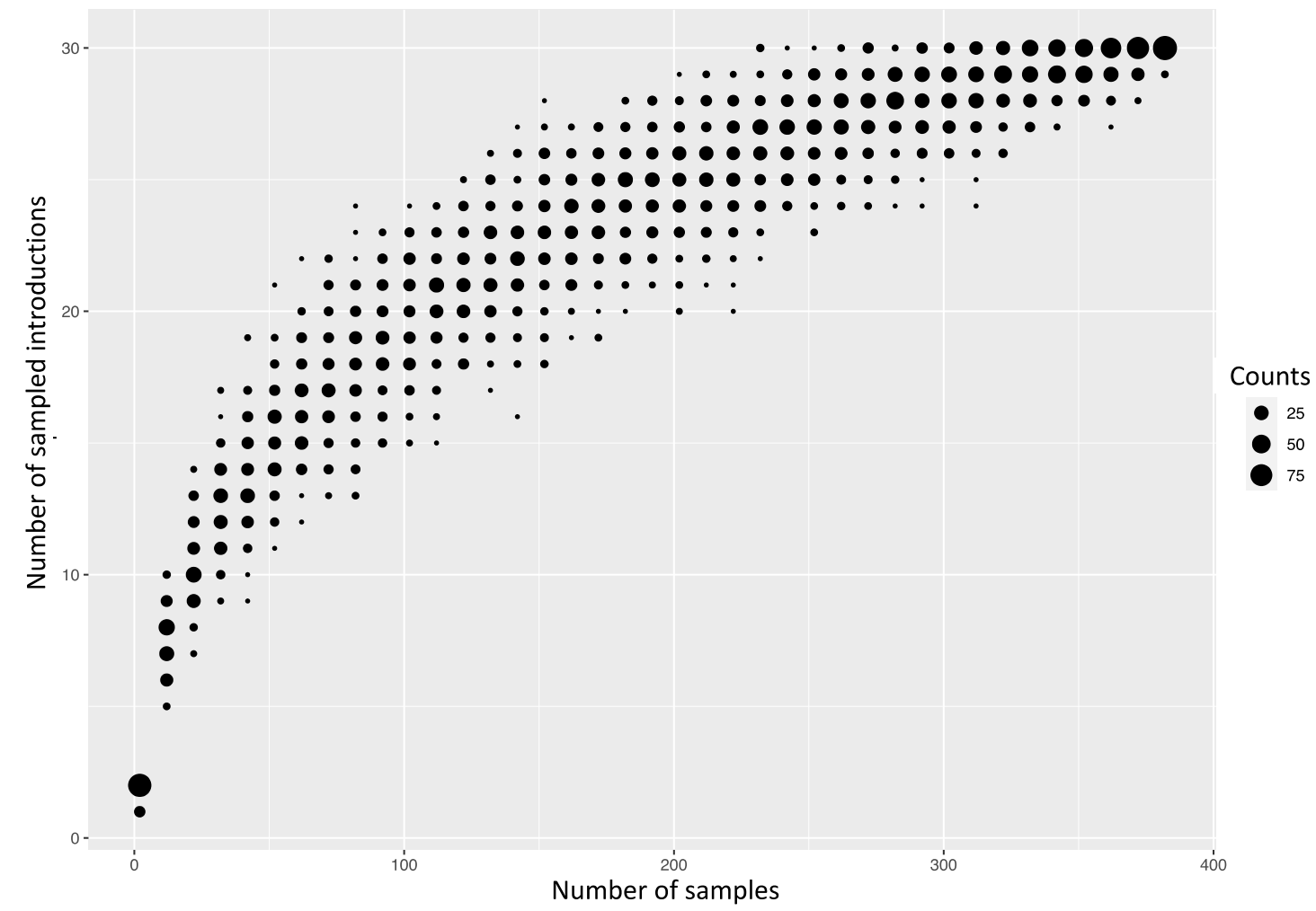

Figure 4. Number of introductions of $\mathrm{A}(\mathrm{H} 1 \mathrm{~N} 1)$ pdm09 viruses into Kenya depending on how many random sequences from Kenya were used to infer introductions.

\subsection{Estimating Population Dynamics of A(H1N1)pdm09 Virus in Kenya from the Local Transmission Clusters}

We estimated the effective reproduction number to be between 1 and 1.5 throughout the study period when we quantified the amount of local transmission on the basis of local transmission clusters (Figure 5A). We inferred seasonal fluctuations in Re between 2009 and 2018, with annual peaks in Re usually occurring at the end of the year and annual drops in Re following the annual peaks, with the estimated median often being below 1 (Figure 5A). The low Re values throughout 2009-2018 are consistent with the occurrence of smaller epidemics in Kenya throughout the study period. Coalescent reconstruction of $\mathrm{A}(\mathrm{H} 1 \mathrm{~N} 1) \mathrm{pdm} 09$ virus occurrence in Kenya revealed (i) seasonal fluctuations in relative genetic diversity after an initial rapid increase during the early pandemic phase, which broadly corresponded to epidemic peaks in the northern and southern hemispheres, (ii) higher genetic diversity (genetic diversity $>10$ ), with greater frequency of seasonal fluctuations observed during 2009-2011 and 2018, and (iii) lower genetic diversity (variation occurring between 1 and 10 in genetic diversity), with relatively weaker seasonal fluctuations sustained from 2012-2017 (Figure 5B). 

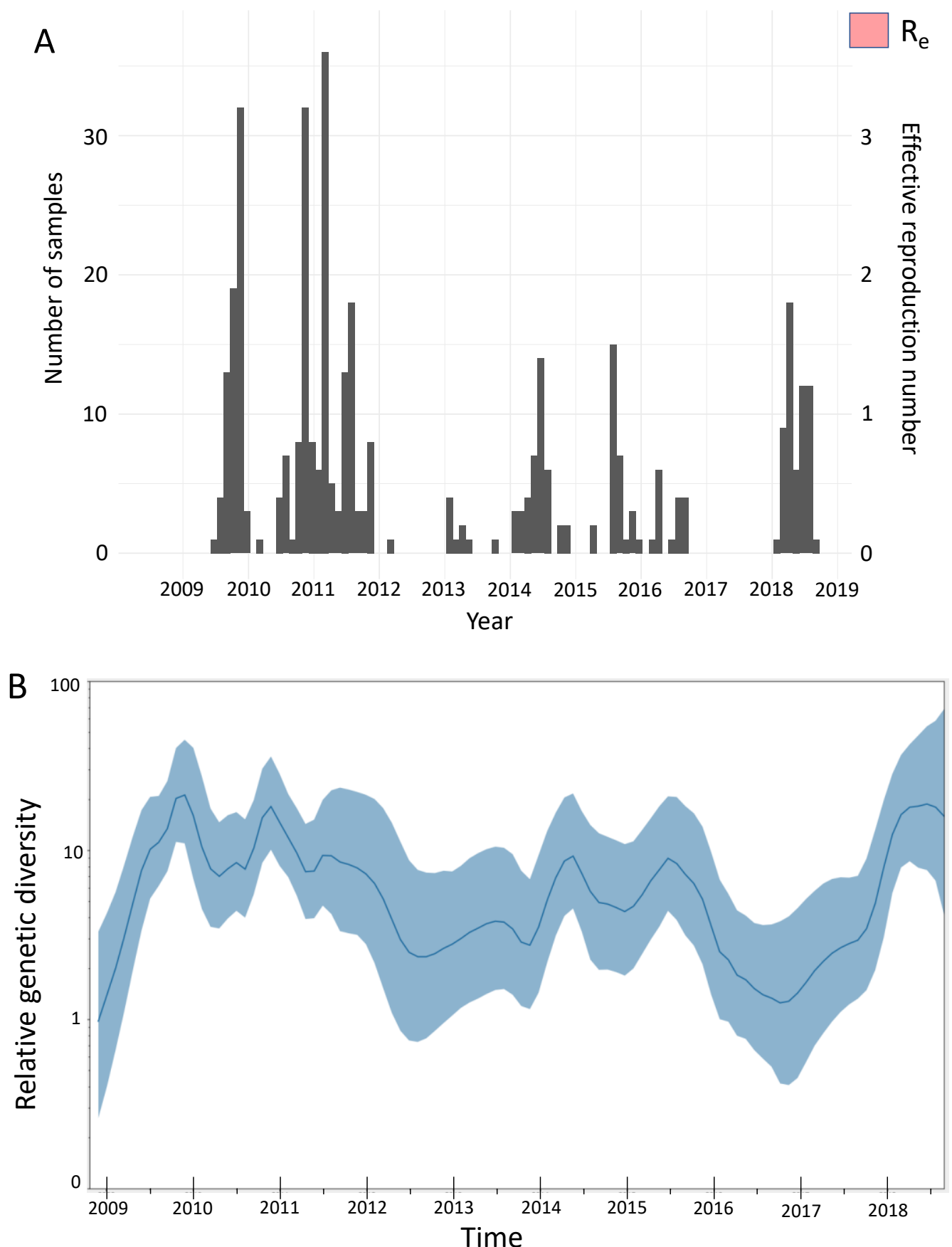

Figure 5. Population dynamics of influenza A(H1N1)pdm09 virus from Kenya, 2009-2018. (A) Estimates of the effective reproduction number through time inferred from all local clusters jointly by using BDSKY analysis. The primary $y$-axis shows the number of sequenced samples, while the secondary $y$-axis shows the effective reproduction number $\left(R_{\mathrm{e}}\right)$. The dark pink section of the $R_{\mathrm{e}}$ values is the mean $R_{e}$ estimate, whereas the light-pink margins denote the $95 \%$ confidence interval; time in years is shown on the $x$-axis. (B) Estimates of the relative genetic diversity through time for influenza A(H1N1)pdm09 virus from Kenya, 2009-2018, resolved using GMRF analysis. The dark-blue line is the mean estimate, and the blue margin denotes the $95 \%$ interval. The relative genetic diversity is shown on the $y$-axis, while time is shown on the $x$-axis. BDSKY, birth-death skyline; GMRF, Gaussian Markov random field. 


\subsection{Regional Spread of A(H1N1)pdm09 Virus in Kenya}

To infer the patterns of spread of A(H1N1)pdm09 virus among three geographical regions of Kenya (central Kenya, western Kenya, and coastal Kenya), we summarized and visualized its geographic spread over time on the basis of significant rates of spread between the geographical regions. We observed significant rates of spread from western Kenya to central and coastal Kenya. Additionally, we observed supported rates of spread from coastal Kenya to western and central Kenya (Figure 6).

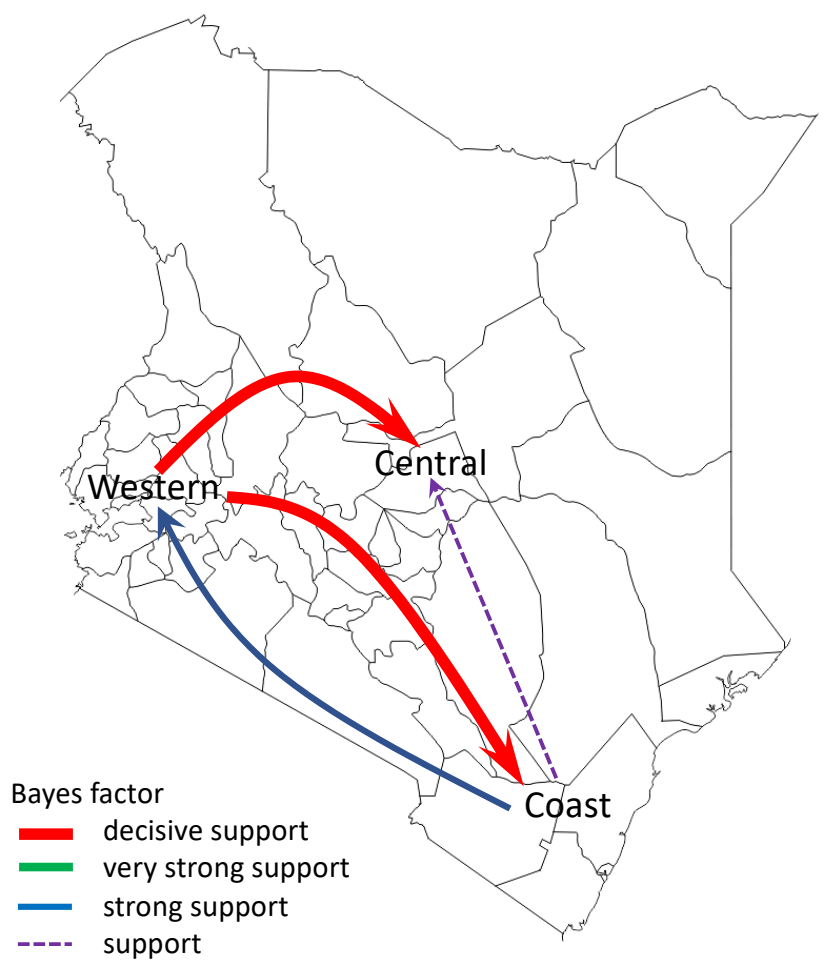

Figure 6. Networks of spread of influenza A(H1N1)pdm09 virus reconstructed using sequence data from Kenya, 2009-2018. Asymmetric pathways of spread between geographical regions of Kenya (central Kenya, western Kenya, and coastal Kenya) were inferred. Colored arrows indicate significant routes of spread from one location state to another, while line thickness represents the degree of statistical support. Red arrows are shown to indicate decisive routes of spread with Bayes factor (BF) support $\geq 1000$; green lines represent very strongly supported routes with $100 \leq \mathrm{BF}<1000$; blue lines indicate strongly supported routes $10 \leq \mathrm{BF}<100$; purple dotted lines indicate supported routes with $3 \leq \mathrm{BF}<10$

\section{Discussion}

We observed multiple A(H1N1)pdm09 virus introductions into Kenya over the study period, although only a few of those introductions instigated local seasonal epidemics that then established local transmission clusters, some of which persisted over several epidemic seasons across Kenya. Furthermore, we show that the seasonal epidemics were associated with a lower number of infections (low estimates of $R_{\mathrm{e}}$ ), consistent with estimates from other regions for $\mathrm{A}(\mathrm{H} 1 \mathrm{~N} 1) \mathrm{pdm} 09$ virus during seasonal epidemics [51], as well as with seasonal fluctuations in virus genetic diversity. Additionally, the spread of A(H1N1)pdm09 virus in Kenya was characterized by countrywide transmission following virus introduction.

Genomic analysis of virus sequence data from Kenya during the pandemic in 2009 reported the introduction of clade 2 and clade 7 viruses in Kenya, although clade 2 viruses did not circulate beyond the introductory foci, while clade 7 viruses disseminated countrywide [52]. Here, through detailed genomic analysis, we extend these earlier observations to show that clade 7 and clade 6 viruses were introduced into Kenya during the 
pandemic, disseminated countrywide, and persisted across multiple epidemics in multiple locations as local transmission clusters. A key question in influenza virus evolution and epidemiology is whether viral lineages can persist at low levels of circulation on local and regional scales or whether new virus strains must be continually reseeded from a globally sustained gene pool [24]. The intensive sampling of viruses during the pandemic in 2009-2010 enabled the molecular epidemiology of IAV to be examined at such a high resolution that the introduction, persistence, and/or fade-out of individual transmission clusters in specific localities could be determined $[5,22]$. Our analysis revealed sustained persistence of seven $\mathrm{A}(\mathrm{H} 1 \mathrm{~N} 1) \mathrm{pdm} 09$ virus transmission clusters for over 2 years, although increased sampling is required to confirm that isolates from other localities are not interspersed within these clusters.

Nonmolecular epidemiological studies have hinted at climate-driven patterns of influenza virus spread in Africa, for example, in Kenya [53] and Uganda [54], where climatic factors have been shown to influence the seasonality of influenza viruses. Therefore, persistence in such African countries might be facilitated by climatic variability, which can generate temporally overlapping epidemics in neighboring regions [24]. Such patterns have been associated with global migration and persistence of influenza viruses in East and Southeast Asia [19]. Our findings support a shifting metapopulation model of circulation of influenza viruses in which viruses may pass through any geographical region for a variable amount of time rather than perpetually circulate in fixed locations, whereby new virus strains can emerge in any geographical region, with the location of the source population changing regularly [19]. Wider and deeper sampling of viruses from understudied tropical and subtropical regions is, therefore, required for a more complete understanding of the regional and the global spread of influenza viruses.

Inclusion of regional and global genome sequences deposited in GISAID significantly improved the power of our phylogenomic analyses, which showed that the Kenyan diversity was part of the global continuum. For example, we showed widespread mixing of Kenyan lineages with global viruses from Africa, Asia, Europe, North America, South America, and Oceania. The use of NGS technology to generate virus sequence data from Kenya enables further scrutiny of the available data to answer other key molecular epidemiological questions. For example, the sequencing depth achieved with NGS may allow for analysis of minority variant populations. Therefore, NGS may facilitate more focused selection of vaccine strains based on strains in circulation in specific regions, which may improve the effectiveness of vaccines.

The study had some limitations. Firstly, the samples analyzed in this study were collected from hospitalized patients with SARI (CDC-Kenya) or viral pneumonia (KCH). This strategy avoided NGS of samples from outpatient cases that may have been critical in reconstructing the patterns of introduction and spread of $\mathrm{A}(\mathrm{H} 1 \mathrm{~N} 1) \mathrm{pdm} 09$ virus in Kenya. Secondly, the analysis in this report only involved the coding regions of the A(H1N1)pdm09 virus gene segments. Although noncoding regions are considered to be conserved, mutations that affect viral replication may occur, and this information may not have been captured in this study. Thirdly, the paucity of sequence data from other African countries limited the analysis of regional patterns of persistence of influenza viruses, since persistence may be facilitated by climatic variability that generates temporally overlapping epidemics in neighboring countries. Lastly, the prioritized samples were selected on the basis of anticipated probability of successful sequencing inferred from the sample's viral load as indicated by the diagnosis $\mathrm{Ct}$ value. Such a strategy ultimately avoided NGS of some samples that may have been critical in reconstructing the patterns of spread of $\mathrm{A}(\mathrm{H} 1 \mathrm{~N} 1) \mathrm{pdm} 09$ virus and persistence of transmission clusters.

In conclusion, although the intensity of influenza surveillance in Africa still lags behind that of other continents, our findings suggest that considerable influenza virus diversity circulates within the continent, including virus lineages that are unique to the region, as reported for Kenya; these lineages may be capable of dissemination to other con- 
tinents through a globally migrating virus population. Further knowledge of the viral lineages that circulate within understudied tropical and subtropical regions is required to understand the full diversity and global ecology of influenza viruses in humans and to inform vaccination strategies within these regions.

Supplementary Materials: The following are available online at www.mdpi.com/article/10.3390/v13101956/s1: Figure S1. Map of Kenya showing the influenza sentinel surveillance sites for SARI used in this study. SARI, Severe Acute Respiratory Illness; GTRH, General Teaching and Referral Hospital; $\mathrm{CH}$, County Hospital; $\mathrm{CRH}$, County and Referral Hospital; NH, National Hospital, Figure S2. Sample processing flow for CDC-Kenya and $\mathrm{KCH}$ surveillance of IAV positive specimens, 2009-2018. Next generation sequencing generated 344 and 39 codon complete $\mathrm{A}(\mathrm{H} 1 \mathrm{N1}$ )pdm09 virus sequences from the CDC-Kenya and $\mathrm{KCH}$ surveillance studies, respectively, which were used for this analysis. CDC, Centers for Disease Control; KCH, Kilifi County Hospital; IAV, influenza A virus.

Author Contributions: Conceptualization, C.N.A., D.J.N., and S.S.C.; methodology, D.C.O., Z.R.d.L., G.K.K., L.M.M., M.O., R.G., and J.R.B.; software, N.F.M., R.G., and J.R.B.; validation, R.G., J.R.B., G.O.E., C.N.A., D.J.N., and S.S.C.; formal analysis, D.C.O. and N.F.M.; investigation, D.C.O., Z.R.d.L., G.K.K., L.M.M., and M.O.; resources, C.N.A., D.J.N., S.S.C., N.A.O., R.G., and J.R.B.; data curation, D.C.O., Z.R.d.L., and G.O.E.; writing-original draft preparation, D.C.O.; writing-review and editing, D.C.O., G.O.E., E.A.H., R.G., J.R.B., C.N.A., D.J.N., and S.S.C.; visualization, D.C.O., N.F.M., and C.N.A.; supervision, C.N.A., D.J.N., S.S.C., R.G., and J.R.B.; project administration, N.A.O., G.O.E., E.A.H., and S.S.C.; funding acquisition, S.S.C. and D.J.N. All authors have read and agreed to the published version of the manuscript.

Funding: The authors D.C.O. and C.N.A. were supported by the Initiative to Develop African Research Leaders (IDeAL) through the DELTAS Africa Initiative [DEL-15-003]. The DELTAS Africa Initiative is an independent funding scheme of the African Academy of Sciences (AAS)'s Alliance for Accelerating Excellence in Science in Africa (AESA), supported by the New Partnership for Africa's Development Planning and Coordinating Agency (NEPAD Agency) with funding from the Wellcome Trust [107769/Z/10/Z] and the UK government. The study was also part funded by a Wellcome Trust grant [1029745] and a USA CDC grant [GH002133]. N.F.M. is supported by the Swiss National Science Foundation (PZEZP3_191891). This paper was published with the permission of the Director of KEMRI. The findings and conclusions in this report are those of the authors and do not necessarily represent the official position of the Centers for Disease Control and Prevention.

Institutional Review Board Statement: The study was conducted according to the guidelines of the Declaration of Helsinki and approved by Scientific Steering Committee (SSC) of KEMRI (KEMRI Scientific and Ethics Review Unit (SERU)) ethics review committee. The National Influenza Sentinel Surveillance Study was approved under SSC numbers 1899, 2558, 2692 and 3044. The KCH Study was approved by KEMRI - Wellcome Trust Research Programme under SERU numbers 1055 and 1433. The SPReD-Kenya Study was approved by KEMRI under SERU number 3044.

Informed Consent Statement: Informed consent was obtained from all subjects involved in the study or their legal guardians.

Data Availability Statement: All generated sequence data were deposited in the GISAID EpiFlu ${ }^{\mathrm{TM}}$ database (https://platform.gisaid.org/epi3/cfrontend; accessed on 11 March 2021) using accession numbers listed in the metadata file in the report's GitHub repository https:/github.com/DCollinsOwuor/H1N1pdm09_Kenya_Phylodynamics/tree/main/Data/; accessed on 11 March 2021.

Conflicts of Interest: The authors declare no conflicts of interest.

\section{References}

1. Novel Swine-Origin influenza A (H1N1) Virus Investigation Team; Dawood, F.S.; Jain, S.; Finelli, L.; Shaw, M.W.; Lindstrom, S.; Garten, R.J.; Gubareva, L.V.; Xu, X.; Bridges, C.B.; et al. Emergence of a novel swine-origin influenza a (H1N1) virus in humans. N. Engl. J. Med. 2009, 360, 2605-2615, https://doi.org/10.1056/nejmoa0903810.

2. Garten, R.J.; Davis, C.T.; Russell, C.; Shu, B.; Lindstrom, S.; Balish, A.; Sessions, W.M.; Xu, X.; Skepner, E.; Deyde, V.; et al. Antigenic and genetic characteristics of swine-origin 2009 a(H1N1) influenza viruses circulating in humans. Science 2009, 325, 197-201, https://doi.org/10.1126/science.1176225. 
3. Smith, G.J.; Vijaykrishna, D.; Bahl, J.; Lycett, S.; Worobey, M.; Pybus, O.; Ma, S.K.; Cheung, C.L.; Raghwani, J.; Bhatt, S.; et al. Origins and evolutionary genomics of the 2009 swine-origin H1N1 influenza A epidemic. Nature 2009, 459, 1122-1125, https://doi.org/10.1038/nature08182.

4. CDC. Outbreak of swine-origin influenza A (H1N1) virus infection-Mexico, March-April 2009. MMWR Morb. Mortal. Weekly Rep. 2009, 58, 467-470, PMID:19444150.

5. Nelson, M.; Spiro, D.; Wentworth, D.; Beck, E.; Fan, J.; Ghedin, E.; Halpin, R.; Bera, J.; Hine, E.; Proudfoot, K.; et al. The early diversification of influenza A/H1N1pdm. PLoS Curr. 2009, 1, RRN1126, https://doi.org/10.1371/currents.rrn1126.

6. Rambaut, A.; Holmes, E. The early molecular epidemiology of the swine-origin A/H1N1 human influenza pandemic. PLoS Curr. 2009, 1, RRN1003, https://doi.org/10.1371/currents.rrn1003.

7. Holmes, E.C.; Ghedin, E.; Halpin, R.A.; Stockwell, T.B.; Zhang, X.-Q.; Fleming, R.; Davey, R.; Benson, C.A.; Mehta, S.; Taplitz, R.; et al. Extensive geographical mixing of 2009 human H1N1 influenza a virus in a single university community. J. Virol. 2011, 85, 6923-6929, https://doi.org/10.1128/jvi.00438-11.

8. Simonsen, L.; Spreeuwenberg, P.; Lustig, R.; Taylor, R.J.; Fleming, D.M.; Kroneman, M.; Van Kerkhove, M.D.; Mounts, A.W.; Paget, W.J.; GLaMOR Collaborating Teams. Global mortality estimates for the 2009 influenza pandemic from the glamor project: A modeling study. PLoS Med. 2013, 10, e1001558, https://doi.org/10.1371/journal.pmed.1001558.

9. Baillie, G.J.; Galiano, M.; Agapow, P.M.; Myers, R.; Chiam, R.; Gall, A.; Palser, A.L.; Watson, S.J.; Hedge, J.; Zambon, M.; et al. Evolutionary dynamics of local pandemic H1N1/2009 influenza virus lineages revealed by whole-genome analysis. J. Virol. 2012, 8, 11-18, https://doi.org/10.1128/jvi.05347-11.

10. Nelson, M.I.; Tan, Y.; Ghedin, E.; Wentworth, D.E.; St. George, K.; Edelman, L.; Beck, E.T.; Fan, J.; Tsan-Yuk Lam, T.; Musser, J.M. et al., Phylogeography of the spring and fall waves of the H1N1/09 pandemic influenza virus in the United States. J. Virol. 2011, 85, 828-834, https://doi.org/10.1128/jvi.01762-10.

11. Zehender, G.; Pariani, E.; Piralla, A.; Lai, A.; Gabanelli, E.; Ranghiero, A.; Ebranati, E.; Amendola, A.; Campanini, G.; Rovida, F.; et al. Reconstruction of the evolutionary dynamics of the a (H1N1) Pdm09 influenza virus in italy during the pandemic and post-pandemic phases. PLOS ONE 2012, 7, e47517, https://doi.org/10.1371/journal.pone.0047517.

12. Venter, M.; Naidoo, D.; Pretorius, M.; Buys, A.; McAnerney, J.; Blumberg, L.; Madhi, S.A.; Cohen, C.; Schoub, B. Evolutionary dynamics of 2009 pandemic influenza a virus subtype H1N1 in South Africa during 2009-2010. J. Infect. Dis. 2012, 206, S166S172, https://doi.org/10.1093/infdis/jis539.

13. Katz, M.A.; Muthoka, P.; Emukule, G.O.; Kalani, R.; Njuguna, H.; Waiboci, L.W.; Ahmed, J.A.; Bigogo, G.; Feikin, D.R.; Njenga, M.K.; et al. Results from the first six years of national sentinel surveillance for influenza in Kenya, July 2007-June 2013. PLoS ONE 2014, 9, e98615, https://doi.org/10.1371/journal.pone.0098615.

14. Katz, M.A.; Lebo, E.; Emukule, G.; Njuguna, H.N.; Aura, B.; Cosmas, L.; Audi, A.; Junghae, M.; Waiboci, L.W.; Olack, B.; et al. Epidemiology, seasonality, and burden of influenza and influenza-like illness in urban and rural Kenya, 2007-2010. J. Infect. Dis. 2012, 206, S53-S60, https://doi.org/10.1093/infdis/jis530.

15. Onyango, C.O.; Njeru, R.; Kazungu, S.; Achilla, R.; Bulimo, W.; Welch, S.; Cane, P.A.; Gunson, R.N.; Hammitt, L.L.; Scott, J.A.G.; et al. Influenza surveillance among children with pneumonia admitted to a district hospital in coastal Kenya, 2007-2010a. J. Infect. Dis. 2012, 206, S61-S67, https://doi.org/10.1093/infdis/jis536.

16. Emukule, G.O.; Khagayi, S.; McMorrow, M.; Ochola, R.; Otieno, N.A.; Widdowson, M.-A.; Ochieng, M.; Feikin, D.R.; Katz, M.A.; Mott, J.A. The burden of influenza and RSV among inpatients and outpatients in Rural Western Kenya, 2009-2012. PLoS ONE 2014, 9, e105543, https://doi.org/10.1371/journal.pone.0105543.

17. Emukule, G.O.; Otiato, F.; Nyawanda, B.O.; Otieno, N.A.; Ochieng, C.A.; Ndegwa, L.K.; Muturi, P.; Bigogo, G.; Verani, J.R.; Muthoka, P.M.; et al. The epidemiology and burden of influenza b/Victoria and b/Yamagata lineages in Kenya, 2012-2016. Open Forum Infect. Dis. 2019, 6, https://doi.org/10.1093/ofid/ofz421.

18. Bedford, T.; Cobey, S.; Beerli, P.; Pascual, M. Global migration dynamics underlie evolution and persistence of human influenza a (H3n2). PLoS Pathog. 2010, 6, e1000918, https://doi.org/10.1371/journal.ppat.1000918.

19. Bahl, J.; Nelson, M.I.; Chan, K.H.; Chen, R.; Vijaykrishna, D.; Halpin, R.A.; Stockwell, T.; Lin, X.; Wentworth, D.; Ghedin, E.; et al. Temporally structured metapopulation dynamics and persistence of influenza A H3N2 virus in humans. Proc. Natl. Acad. Sci. USA 2011, 108, 19359-19364, https://doi.org/10.1073/pnas.1109314108.

20. Lemey, P.; Rambaut, A.; Bedford, T.; Faria, N.R.; Bielejec, F.; Baele, G.; Russell, C.; Smith, D.; Pybus, O.; Brockmann, D.; et al. Unifying viral genetics and human transportation data to predict the global transmission dynamics of human influenza H3N2. PLoS Pathog. 2014, 10, e1003932, https://doi.org/10.1371/journal.ppat.1003932.

21. Bedford, T.; Riley, S.; Barr, I.G.; Broor, S.; Chadha, M.; Cox, N.J.; Daniels, R.S.; Gunasekaran, C.P.; Hurt, A.C.; Kelso, A.; et al. Data from: Global circulation patterns of seasonal influenza viruses vary with antigenic drift. Nature 2015, 523, 217-220, https://doi.org/10.5061/dryad.pc641.

22. Lemey, P.; Suchard, M.; Rambaut, A. Reconstructing the initial global spread of a human influenza pandemic: A Bayesian spatial-temporal model for the global spread of H1N1pdm. PLoS Curr. 2009, 1, RRN1031, https://doi.org/10.1371/currents.rrn1031.

23. Galiano, M.; Agapow, P.-M.; Thompson, C.; Platt, S.; Underwood, A.; Ellis, J.; Myers, R.; Green, J.; Zambon, M. Evolutionary pathways of the pandemic influenza a (H1N1) 2009 in the UK. PLoS ONE 2011, 6, e23779, https://doi.org/10.1371/journal.pone.0023779. 
24. Nelson, M.I.; Njouom, R.; Viboud, C.; Niang, M.N.D.; Kadjo, H.; Ampofo, W.; Adebayo, A.; Tarnagda, Z.; Miller, M.A.; Holmes, E.C.; et al. Multiyear Persistence of 2 Pandemic A/H1N1 Influenza Virus Lineages in West Africa. J. Infect. Dis. 2014, 210, 121125, https://doi.org/10.1093/infdis/jiu047.

25. Hirve, S.; Newman, L.P.; Paget, J.; Azziz-Baumgartner, E.; Fitzner, J.; Bhat, N.; Vandemaele, K.; Zhang, W. Influenza Seasonality in the Tropics and Subtropics-When to Vaccinate? PLOS ONE 2016, 11, e0153003.

26. Newman, L.P.; Bhat, N.; Fleming, J.A.; Neuzil, K.M. Global influenza seasonality to inform country-level vaccine programs: An analysis of WHO FluNet influenza surveillance data between 2011 and 2016. PLoS ONE 2018, 13, e0193263, https://doi.org/10.1371/journal.pone.0193263.

27. $\mathrm{Ng}$, S.; Gordon, A. Influenza burden and transmission in the tropics. Curr. Epidemiol. Rep. 2015, 2, 89-100, https://doi.org/10.1007/s40471-015-0038-4.

28. Viboud, C.; Nelson, M.I.; Tan, Y.; Holmes, E.C. Contrasting the epidemiological and evolutionary dynamics of influenza spatial transmission. Philos. Trans. R. Soc. B Biol. Sci. 2013, 368, 20120199, https://doi.org/10.1098/rstb.2012.0199.

29. Nokes, D.J.; Ngama, M.; Bett, A.; Abwao, J.; Munywoki, P.K.; English, M.; Scott, J.A.G.; Cane, P.A.; Medley, G.F. Incidence and severity of respiratory syncytial virus pneumonia in rural Kenyan children identified through hospital surveillance. Clin. Infect. Dis. 2009, 49, 1341-1349, https://doi.org/10.1086/606055.

30. Scott, J.A.G.; Bauni, E.; Moisi, J.C.; Ojal, J.; Gatakaa, H.; Nyundo, C.; Molyneux, C.S.; Kombe, F.; Tsofa, B.; Marsh, K.; et al. Profile: The Kilifi health and demographic surveillance system (KHDSS). Int. J. Epidemiol. 2012, 41, 650-657, https://doi.org/10.1093/ije/dys062.

31. CDC. Introduction and transmission of 2009 pandemic influenza A (H1N1) virus - Kenya, June-July 2009. MMWR Morb. Mortal. Weekly Rep. 2009, 58, 1143-1146.

32. Osoro, E.M. Hospitalized patients with pandemic (H1N1) 2009, Kenya. Emerg. Infect. Dis. 2011, 17, 1744-1746, https://doi.org/10.3201/eid1709.100992.

33. Feikin, D.R.; Olack, B.; Bigogo, G.M.; Audi, A.; Cosmas, L.; Aura, B.; Burke, H.; Njenga, M.K.; Williamson, J.; Breiman, R.F. The burden of common infectious disease syndromes at the clinic and household level from population-based surveillance in rural and urban Kenya. PLoS ONE 2011, 6, e16085, https://doi.org/10.1371/journal.pone.0016085.

34. Hammitt, L.L.; Kazungu, S.; Welch, S.; Bett, A.; Onyango, C.O.; Gunson, R.N.; Scott, J.A.G.; Nokes, D.J. Added value of an oropharyngeal swab in detection of viruses in children hospitalized with lower respiratory tract infection. J. Clin. Microbiol. 2011, 49, 2318-2320, https://doi.org/10.1128/jcm.02605-10.

35. Owuor, D.C.; Ngoi, J.M.; Otieno, J.R.; Otieno, G.P.; Nyasimi, F.M.; Nyiro, J.U.; Agoti, C.N.; Chaves, S.S.; Nokes, D.J. Genetic characterization of influenza A(H3N2) viruses circulating in coastal Kenya, 2009-2017. Influ. Other Respir. Viruses 2020, 14, 320330, https://doi.org/10.1111/irv.12717.

36. Zhou, B.; Wentworth, D.E. Influenza a virus molecular virology techniques. J. Clin. Microbiol. 2012, 865, 175-192, https://doi.org/10.1007/978-1-61779-621-0_11.

37. Shepard, S.S.; Meno, S.; Bahl, J.; Wilson, M.M.; Barnes, J.; Neuhaus, E. Viral deep sequencing needs an adaptive approach: IRMA, the iterative refinement meta-assembler. BMC Genom. 2016, 17, 708, https://doi.org/10.1186/s12864-016-3030-6.

38. Larsson, A. AliView: A fast and lightweight alignment viewer and editor for large datasets. Bioinformatics 2014, 30, 3276-3278, https://doi.org/10.1093/bioinformatics/btu531.

39. Vaidya, G.; Lohman, D.J.; Meier, R. SequenceMatrix: Concatenation software for the fast assembly of multi-gene datasets with character set and codon information. Cladistics 2011, 27, 171-180, https://doi.org/10.1111/j.1096-0031.2010.00329.x.

40. Nguyen, L.-T.; Schmidt, H.; Von Haeseler, A.; Minh, B.Q. IQ-TREE: A fast and effective stochastic algorithm for estimating maximum-likelihood phylogenies. Mol. Biol. Evol. 2014, 32, 268-274, https://doi.org/10.1093/molbev/msu300.

41. Kalyaanamoorthy, S.; Minh, B.Q.; Wong, T.; Von Haeseler, A.; Jermiin, L.S. ModelFinder: Fast model selection for accurate phylogenetic estimates. Nat. Methods 2017, 14, 587-589, https://doi.org/10.1038/nmeth.4285.

42. Yu, G.; Smith, D.K.; Zhu, H.; Guan, Y.; Lam, T.T. An r package for visualization and annotation of phylogenetic trees with their covariates and other associated data. Methods Ecol. Evol. 2016, 8, 28-36, https://doi.org/10.1111/2041-210x.12628.

43. Han, A.X.; Parker, E.; Scholer, F.; Maurer-Stroh, S.; Russell, C.A. Phylogenetic clustering by linear integer programming (Phyclip). Mol. Biol. Evol. 2019, 36, 1580-1595, https://doi.org/10.1093/molbev/msz053.

44. Sagulenko, P.; Puller, V.; Neher, R.A. TreeTime: Maximum-likelihood phylodynamic analysis. Virus Evol. 2018, 4, vex042, https://doi.org/10.1093/ve/vex042.

45. Stadler, T.; Kühnert, D.; Bonhoeffer, S.; Drummond, A. Birth-death skyline plot reveals temporal changes of epidemic spread in HIV and hepatitis C virus (HCV). Proc. Natl. Acad. Sci. USA 2012, 110, 228-233, https://doi.org/10.1073/pnas.1207965110.

46. Müller, N.F.; Wüthrich, D.; Goldman, N.; Sailer, N.; Saalfrank, C.; Brunner, M.; Augustin, N.; Seth-Smith, H.M.; Hollenstein, Y.; Syedbasha, M.; et al. Characterising the epidemic spread of influenza A/H3N2 within a city through phylogenetics. PLoS Pathog. 2020, 16, e1008984, https://doi.org/10.1371/journal.ppat.1008984.

47. Minin, N.; Bloomquist, E.W.; Suchard, M.A. Smooth Skyride through a rough Skyline: Bayesian coalescent-based inference of population dynamics. Mol. Biol. Evol. 2008, 25, 1459-1471, https://doi.org/10.1093/molbev/msn090.

48. Suchard, M.A.; Lemey, P.; Baele, G.; Ayres, D.L.; Drummond, A.J.; Rambaut, A. Bayesian phylogenetic and phylodynamic data integration using BEAST 1.10. Virus Evol. 2018, 4, vey016, https://doi.org/10.1093/ve/vey016.

49. Lemey, P.; Rambaut, A.; Drummond, A.; Suchard, M.A. Bayesian phylogeography finds its roots. PLoS Comput. Biol. 2009, 5, e1000520, https://doi.org/10.1371/journal.pcbi.1000520. 
50. Bielejec, F.; Baele, G.; Vrancken, B.; Suchard, M.A.; Rambaut, A.; Lemey, P. Spread3: Interactive visualization of spatiotemporal history and trait evolutionary processes. Mol. Biol. Evol. 2016, 33, 2167-2169, https://doi.org/10.1093/molbev/msw082.

51. Biggerstaff, M.; Cauchemez, S.; Reed, C.; Gambhir, M.; Finelli, L. Estimates of the reproduction number for seasonal, pandemic, and zoonotic influenza: A systematic review of the literature. BMC Infect. Dis. 2014, 14, 480, https://doi.org/10.1186/1471-233414-480.

52. Gachara, G.; Symekher, S.; Otieno, M.; Magana, J.; Opot, B.; Bulimo, W. Whole genome characterization of human influenza A(H1N1)pdm09 viruses isolated from Kenya during the 2009 pandemic. Infect. Genet. Evol. 2016, 40, 98-103, https://doi.org/10.1016/j.meegid.2016.02.029.

53. Emukule, G.O.; Mott, J.A.; Spreeuwenberg, P.; Viboud, C.; Commanday, A.; Muthoka, P.; Munywoki, P.K.; Nokes, D.J.; Van Der Velden, K.; Paget, J.W. Influenza activity in K enya, 2007-2013: Timing, association with climatic factors, and implications for vaccination campaigns. Influenza Other Respir. Viruses 2016, 10, 375-385, https://doi.org/10.1111/irv.12393.

54. Yang, J.-R.; Hsu, S.-Z.; Kuo, C.-Y.; Huang, H.-Y.; Huang, T.-Y.; Wang, H.-C.; Liu, M.-T. An epidemic surge of influenza A(H3N2) virus at the end of the 2016-2017 season in Taiwan with an increased viral genetic heterogeneity. J. Clin. Virol. 2018, 99-100, 1521, https://doi.org/10.1016/j.jcv.2017.12.012. 